\title{
WegenerNet climate station network region Feldbach, Austria: network structure, processing system, and example results
}

\author{
T. Kabas, A. Leuprecht, C. Bichler, and G. Kirchengast \\ Wegener Center for Climate and Global Change (WEGC), and Institute for Geophysics, Astrophysics and \\ Meteorology/Institute of Physics (IGAM/IP), University of Graz, Graz, Austria
}

Received: 10 December 2010 - Revised: 21 February 2011 - Accepted: 24 February 2011 - Published: 9 March 2011

\begin{abstract}
The WegenerNet climate station network is a pioneering weather and climate observation experiment at very high resolution in southeastern Austria. The network comprises 151 meteorological stations within a limited area of approximately $20 \mathrm{~km} \times 15 \mathrm{~km}$ centered near the town of Feldbach. Measurements include the parameters air temperature, relative humidity, precipitation amount, and others at selected stations (e.g. wind and soil parameters). The temporal sampling is 5 min except $30 \mathrm{~min}$ sampling of soil measurements. All data pass a Quality Control System and the provided data products include station data $(\sim 1.4 \mathrm{~km} \times 1.4 \mathrm{~km}$ grid) and gridded data $\left(1 \mathrm{~km} \times 1 \mathrm{~km}\right.$ and $0.01^{\circ} \times 0.01^{\circ}$ grids) on various temporal scales (from $5 \mathrm{~min}$ to annual). For application purposes all data are available in near real time (data latency less than $1-2 \mathrm{~h}$ in standard operation) via the WegenerNet data portal (www.wegenernet.org).
\end{abstract}

\section{Introduction}

Analyses of climate variability on regional or finer scales are a great challenge for the climate change and impact research community. Investigations of local characteristics and further questions in microclimatology are limited by the availability of high-resolution temporal and spatial observations. Operationally, such in-situ observations are yet not available according to the authors' knowledge. Only temporary field campaigns are conducted, partially backed by further measuring methods. In the Convective and Orographically Induced Precipitation Study, for instance, various methods were combined including radar measurements and highly resolved station observations in a limited area in southwest Germany (Wulfmeyer et al., 2008). Such comparative studies demonstrate the technical possibilities to fullfill the users' demand for high resolution data besides the usage of in-situ measurements (also compare www.microradarnet.net).

However, in order to obtain accurate information these measurements have to be calibrated on and validated against dense observational station data. For this purpose, and lot of other research applications as well, long-term station

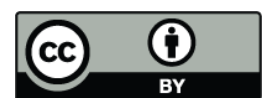

Correspondence to: T. Kabas

(thomas.kabas@uni-graz.at) observations are required. The current paper presents the very dense network WegenerNet located in southeast Austria which is intended to provide such long-term observational records. Since the beginning of 2007, regular measurements of 151 meteorological stations and derived gridded data are provided. In this paper, a brief overview of the study region and the network structure is given in Sect. 2. Section 3 introduces the data processing followed by the provided weather and climate data products (Sect. 4). The resulting high-resolution maps of two exemplary events are illustrated in Sect. 5 and finally, concluding remarks are presented in Sect. 6.

\section{Network structure and measured parameters}

The WegenerNet is located in southeastern Styria, Austria, centered near the town of Feldbach. Results of previous studies underline the sensitivity of southeast Austria to changes in climate conditions (e.g. Auer et al., 2001; Prettenthaler et al., 2007; Heinrich, 2008; Kabas et al., 2011) and a limited area of approximately $20 \mathrm{~km} \times 15 \mathrm{~km}$ was selected as study area for this observational experiment. Within the complex landscape of Austria, the enclosed territory is part of the Alpine foreland in which lowlands and hilly landscapes with comparably low altitudes represent the prevailing landforms (257-520 $\mathrm{m}$ station altitudes). In the study region, 
Table 1. Different types of WegenerNet stations and the measured parameters completed by their temporal resolution. Heated rain gauges are marked by *.

\begin{tabular}{|c|c|c|c|}
\hline Station type & Number of stations & Parameters & Temporal resolution \\
\hline Base station & 127 & Air temperature, Relative humidity, Precipitation amount & $5 \mathrm{~min}$ \\
\hline \multirow{3}{*}{ Special base station } & \multirow{2}{*}{11} & Air temperature, Relative humidity, Precipitation amount & $5 \min$ \\
\hline & & Soil temperature, $\mathrm{pF}$-value & $30 \mathrm{~min}$ \\
\hline & 1 & Air temperature, Relative humidity & $5 \mathrm{~min}$ \\
\hline \multirow{3}{*}{ Primary station } & \multirow{3}{*}{11} & Air temperature, Relative humidity, Precipitation amount* & $5 \mathrm{~min}$ \\
\hline & & Average wind speed and direction & $5 \mathrm{~min}$ \\
\hline & & Peak gust and its direction & $5 \mathrm{~min}$ \\
\hline \multirow{5}{*}{ Reference station } & \multirow{5}{*}{1} & Air temperature, Relative humidity, Precipitation amount ${ }^{*}$ & $5 \mathrm{~min}$ \\
\hline & & Average wind speed and direction & $5 \mathrm{~min}$ \\
\hline & & Peak gust and its direction & $5 \mathrm{~min}$ \\
\hline & & Soil temperature, $\mathrm{pF}$-value & $30 \mathrm{~min}$ \\
\hline & & Air pressure, Net radiation & $5 \mathrm{~min}$ \\
\hline
\end{tabular}

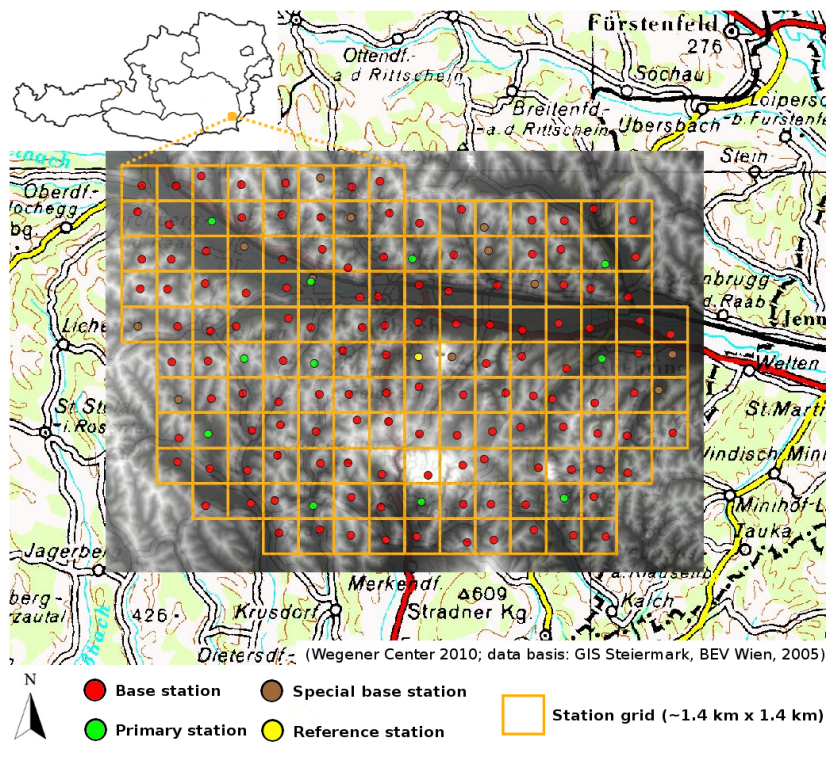

Figure 1. The WegenerNet study region (orographic map) in Austria and the station locations in the station grid.

which is characterized by the river Raab valley and the surrounding hilly landscape, 151 meteorological stations are arranged based on an approximately $1.4 \mathrm{~km} \times 1.4 \mathrm{~km}$ grid (see Fig. 1). The station locations are determined in consideration of representative meteorological conditions as well as technical needs of the installed sensors depending on the station type and the measured parameters.

As shown in Table 1, the WegenerNet stations are separated in four different types. Base stations measure the main parameters air temperature, relative humidity and precipita-
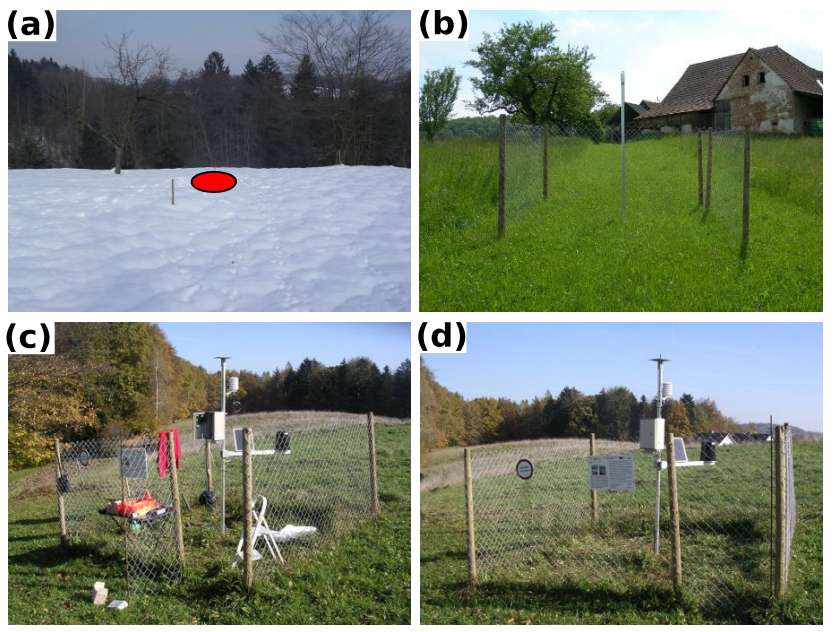

Figure 2. Setup of the WegenerNet climate station No. 6 during the year 2006.

tion amount. Selected further stations include measurements of soil and wind parameters at suitable sites within the network. At the reference station, the main parameters as well as soil and wind parameters are completed by measurements of air pressure and net radiation. The temporal sampling is 5 min with the exception of soil parameters sampled every $30 \mathrm{~min}$ (as they react more inert at short time scales).

The network was mainly set up during the year 2006 supported by partners in the region and students of the University of Graz. Figure 2 illustrates the main steps of construction: (a) location selection, (b) infrastructure setup, (c) sensor installation and (d) test mode. Further information on the network implementation is given in Kirchengast et al. 
Table 2. Quality layers of the Quality Control System.

\begin{tabular}{clc}
\hline Layer No. & Quality layer & Quality flag \\
\hline 0 & operational check & 1 \\
1 & availability check & 2 \\
2 & sensor check & 4 \\
3 & climatological check & 8 \\
4 & time variability check & 16 \\
5 & intra-station consistency check & 32 \\
6 & inter-station consistency check & 64 \\
7 & external reference check & 128 \\
\hline
\end{tabular}

(2008). Data started to be delivered in the fall of 2006 and regular measurements of 150 stations are provided since January 2007. Due to the implementation of additional sensors at the reference station, preparatory modifications of the technical infrastructure were needed and data are available since mid-October 2007.

\section{Processing system}

The collected data are integrated in an automatic processing system including data transfer, quality control, product generation, and presentation. Each station is equipped with an internet-attached data logger and the measurements are transmitted as binary files via GPRS to the WegenerNet server in $1 \mathrm{~h}$ intervals. Within this hourly schedule, all stations are split in 10 packages with a 5 min time lag in transfer starting every full hour. The incoming raw data files of measured parameters as well as several housekeeping values of the data logger (e.g. power supply level, internal temperature and humidity conditions) are stored in a relational database (PostgreSQL) in which important metadata of technical specifications and information on the station locations are recorded as well.

After the hourly cycle of data transfer, the raw data pass the Quality Control System (QCS) in which the measurements are checked for their technical and physical plausibility. The QCS consists of seven quality layers (see Table 2) holding various tests on the data. The quality control starts with specifications of the installed sensors to detect malfunctions right at the beginning. Next, the climatological plausibility is determined by climatic bounds on monthly scale which are derived from two long-term stations of the Austrian Central Institute for Meteorology and Geodynamics (ZAMG) located in the study region. The next layer indicates interfering signals and sensor errors (e.g. frozen measurement devices) by analyzing the temporal variability and constancy within parameter-specific periods. In the intra-stational consistency check, meteorological and physical relations of measured parameters at each station are compared. For example, the peak gust is needed to be higher than the average wind speed and higher amounts of precip-
Table 3. Maximum period of linearly interpolated data.

\begin{tabular}{lc}
\hline Parameters & Maximum period \\
\hline Air temperature, Relative humidity & $30 \mathrm{~min}$ \\
Precipitation amount & $15 \mathrm{~min}$ \\
Average wind speed and direction & $15 \mathrm{~min}$ \\
Peak gust and its direction & $15 \mathrm{~min}$ \\
Soil temperature, pF-value & $180 \mathrm{~min}$ \\
Air pressure & $60 \mathrm{~min}$ \\
Net raditation & $15 \mathrm{~min}$ \\
\hline
\end{tabular}

itation require increased humidity conditions. The following quality layer of inter-stational consistency is based on the spatial density of measured main parameters. According to a candidate-reference method, neighboring stations are selected as references in consideration of defined requirements for each parameter (e.g. distance, topography, altitude difference). As a result, the small-scale variability could be included in more detail in the detection of errors like blocked rain gauges or manual water input by a person. In the final layer, WegenerNet data is compared with external references as used for the comparison of air pressure measurements at the reference station with the two ZAMG stations in the study area. In the course of the QCS processing, each data value gets marked by an appropriate quality flag. If some test fails in layer $i$ the $i$-th bit of the flag is set (see Table 2). Thus a quality flag 0 corresponds to valid data. Looking at data records within periods of active observations between 2007 and 2010, 93.9\% of measurements are marked by a flag 0 . Out of values with flags of higher order, only one fifth belongs to technical problems and the majority of values identified as erroneous is related to meteorological and/or climatological inconsistencies.

Subsequently to the quality control, only measurements of best quality (flag 0) are considered for the Data Product Generator (DPG) processing. In the DPG, the time series of all parameters are checked for gaps resulting in missing measurements or erroneous values detected by the QCS. For each parameter a maximum period of consecutively missing data is defined (see Table 3) and short periods are linearly interpolated. In case of longer gaps they get filled by a predefined missing value. Further processes of gap-filling and grid interpolation are realized for the main parameters and briefly described in the two following steps. First, data of neighboring stations defined in the QCS are used for inverse-distancesquared weighting interpolation (IDSWI) of still missing values if a sufficient number of neighbors is available. For air temperature, the interpolation is performed at the reference altitude of $300 \mathrm{~m}$. The required lapse rate to project to this altitude is calculated by linear regression analysis from temperature data of stations and their altitudes for every $1 \mathrm{~h}$ time window. Next, gridded data are derived from neighboring sites by IDSWI. Regular grids are calculated in UTM 
$(1 \mathrm{~km} \times 1 \mathrm{~km}$ grid $)$ and longitude/latitude $\left(0.01^{\circ} \times 0.01^{\circ}\right.$ grid $)$ coordinates. For air temperature, a $10 \mathrm{~m} \times 10 \mathrm{~m}$ digital elevation model is used to complement the gridded data at $300 \mathrm{~m}$ altitude by two orographic grids: one is computed for the mean altitude of each grid cell (T_zAvgTerr) and the other one for the altitude of the central point of the cell (T_zTerrain). After the grid interpolation, still missing station data of the main parameters are derived from the grid by IDSWI. Air temperature is interpolated at the reference altitude and projected to the station altitude afterwards. Out of missing input station data for the DPG processing from 2007 to $2010,22.9 \%$ are filled by linear interpolation, $36.9 \%$ are interpolated by inverse-distance-squared weighting using data of neighboring stations and $25.8 \%$ are derived from the grid by IDSWI. The remaining $14.4 \%$ cannot be interpolated which corresponds to more than $99 \%$ of overall data availability. Finally, the DPG uses the 5 min data and produces weather and climate data products for station and gridded data on various temporal scales (from half-hourly to annual). Both subsystems (QCS and DPG) are realized by the programming language Python.

\section{Data products and availability}

The provided weather and climate data products consist of station data and gridded data. Regular grids are realized for the main parameters in $1 \mathrm{~km} \times 1 \mathrm{~km}(\mathrm{UTM})$ and $0.01^{\circ} \times 0.01^{\circ}$ (longitude/latitude) resolution. The temporal resolution includes $5 \mathrm{~min}$, half-hourly, hourly, daily, seasonal, and annual data. For application purposes the resulting data products are available via the bi-lingual (dt, en) WegenerNet data portal (www.wegenernet.org). Presently (December 2010), the main web interface is still online as a system in which MapServer is used to import spatial data by its database interface and to generate images out of static geographic formats. Furthermore, station data are visualized as time series by the scripting language PHP. Since February 2010, the visualization of gridded data products is a first step to a new data portal based on OpenLayers. In this GIS framework, all geographic information (e.g. OpenStreetMap) is displayed with MapServer. Maps of meteorological parameters are generated on the fly by a Python CGI script and transparently overlayed on optional base layers. In this way, station data and gridded data are visualized and furthermore prepared for download in common data formats (csv, NetCDF). In terms of availability, measured data and calculated data products are provided in near real time (data latency less than $1-2 \mathrm{~h}$ in standard operation).

\section{Results on $1 \mathrm{~km}$-scale resolution}

The resulting WegenerNet data sets enable a detailed view on small-scale variability as briefly shown in the two following examples.
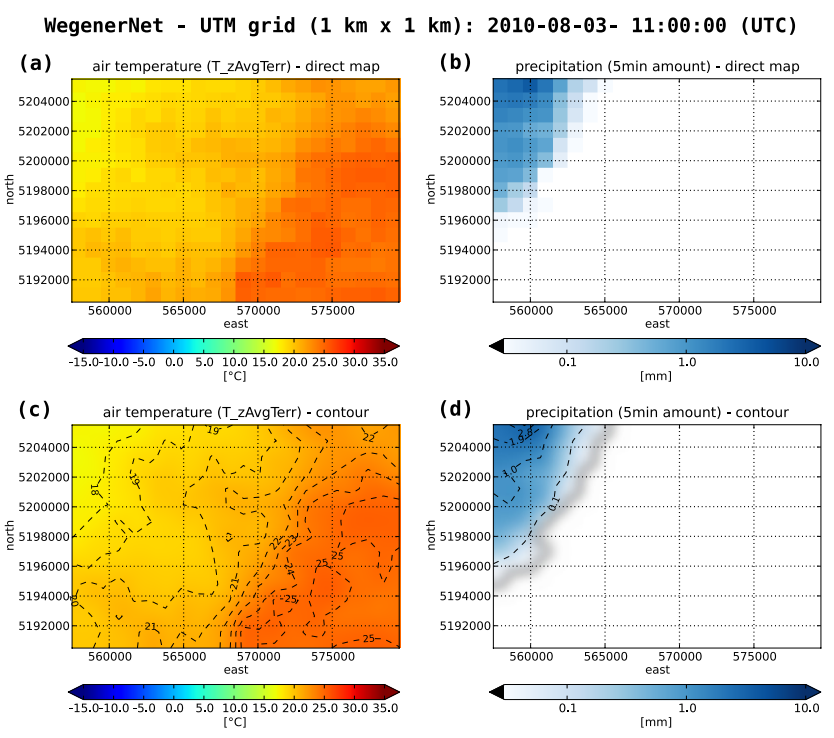

Figure 3. Temperature and precipitation conditions on August 3, 2010 , in the WegenerNet region at $1 \mathrm{~km}$ resolution in UTM coordinates (dotted lines): direct map of grid cells in (a) and (b), smoothed cell boundaries and inserted contours (dashed lines) in (c) and (d). Precipitation amounts ( $5 \mathrm{~min})$ are given on a logarithmic scale.

In Fig. 3 a frontal system reaches the study area from the Northwest. The prevailing temperature conditions (T_zAvgTerr) and precipitation amounts $(5 \mathrm{~min}$ ) are shown at an exemplary time step in two ways. The upper part (Fig. 3a and $b$ ) illustrates the direct map of the grid with clearly recognizable $1 \mathrm{~km} \times 1 \mathrm{~km}$ grid cells. In Fig. $3 \mathrm{c}$ and d, the cell boundaries are smoothed and dashed contours are inserted. Looking at Fig. 3a, a strong temperature gradient occurs from the Northwest to the Southeast. In the forefront of areas with measureable precipitation in Fig. 3d, which ranges up to amounts of about $3 \mathrm{~mm}$ per $5 \mathrm{~min}$, the cold air extends to the temperature difference of about $2{ }^{\circ} \mathrm{C}$ illustrated by the contours in Fig. 3c. Thus, the north-western part has already cooled down to about $18^{\circ} \mathrm{C}$, however, still warmer conditions of about $24^{\circ} \mathrm{C}$ appear in the Southeast. Over the next hours, precipitation can be observed throughout the study area and lead to daily amounts up to $19 \mathrm{~mm}$.

The second example demonstrates the temporal and spatial variability observed for precipitation. Figure 4 shows $5 \mathrm{~min}$ amounts at six timesteps of a summer precipitation event which passed the WegenerNet within one hour. As in the example before, precipitation is observed at the north-western climate stations first. In the next two timesteps (Fig. 4b and c), a second precipitation cell emerges close to the center of the study area and the precipitation amounts increase to more than $2.5 \mathrm{~mm}$ per $5 \mathrm{~min}$. The two cells merge in Fig. $4 \mathrm{~d}$ with up to $3.3 \mathrm{~mm}$ and finally leave the region southwards. 

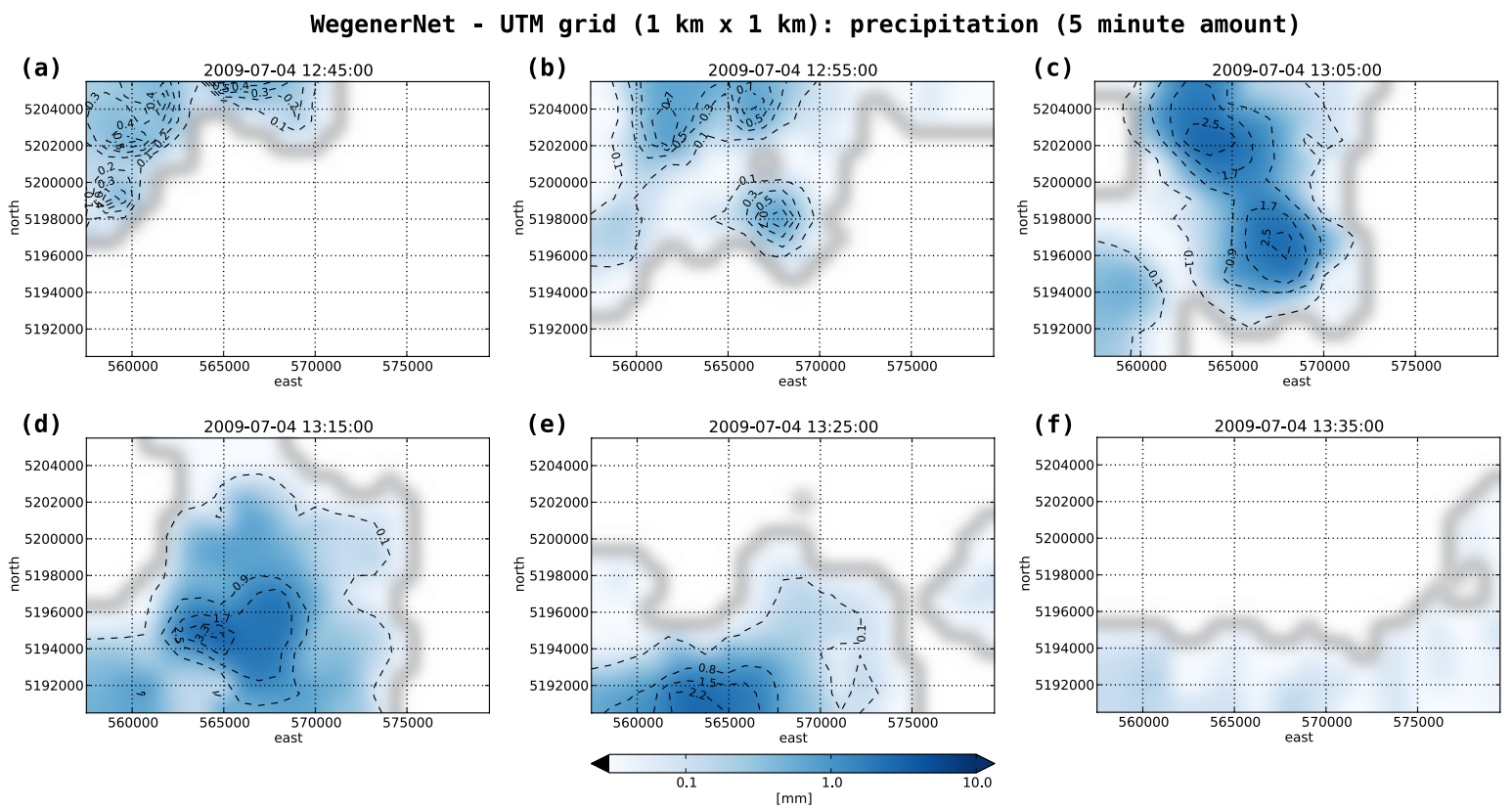

Figure 4. Temporal and spatial variability of precipitation on 4 July 2009, at $1 \mathrm{~km}$ resolution in UTM coordinates (dotted lines). Amounts with 5 min sampling are shown on a logarithmic scale at every second timestep within one hour.

\section{Conclusions}

The climate station network WegenerNet provides a new data set of very high resolution in the southeastern part of Austria. Local weather and climate conditions are observed by 151 meteorological stations with an average distance between stations of approximately $1.4 \mathrm{~km}$. An automatic processing system was implemented including the data transfer in $1 \mathrm{~h}$ intervals and the quality control of measurements in seven quality layers. Furthermore, regular grids are computed for the main parameters air temperature, relative humidity and precipitation amount at $1 \mathrm{~km}$ and $0.01^{\circ}$ resolution, respectively. Station data and gridded data are prepared on various temporal scales and available for data users in near real time at the WegenerNet data portal.

This study confirms the applicability of the WegenerNet as a long-term observation network for the climate and climate impact research community. A range of possible research applications include convective events, terrain climatology, extreme events and further studies on local scale variability. The high resolution in space and time allows the evaluation of remote sensing techniques (e.g. radar) and the validation of small-scale dynamics in a model and analysis system (e.g. Haiden et al., 2010). Furthermore, the findings can be a basis for weather- and climate-related decisions in the study region such as questions of water balance assessments, agricultural productivity and area development.
Acknowledgements. The climate station network WegenerNet was funded by the Austrian government, the state of Styria, the 27 municipalities in the study region, the City of Graz and the University of Graz. The authors also thank all our regional partners and further sponsors supporting the network setup and its operation. Furthermore, we thank the Austrian Central Institute for Meteorology and Geodynamics (ZAMG) for providing comparison data from their observational station network.

Edited by: I. Auer

Reviewed by: two anonymous referees

\section{SC by the Swiss Academy of Sciences.}

\section{References}

Auer, I., Böhm, R., and Schöner, W.: Austrian long-term climate 1767-2000, multiple instrumental climate time series from Central Europe, Österreichische Beiträge zu Meteorologie und Geophysik 25, Zentralanstalt für Meteorologie und Geodynamik, Wien, 2001.

Haiden, T., Kann, A., Wittmann, C., Pistotnik, G., Bica, B., and Gruber, C.: The Integrated Nowcasting through Comprehensive Analysis (INCA) system and its validation over the Eastern Alpine region, Weather Forecast., in press, doi:10.1175/2010WAF2222451.1, 2010.

Heinrich, G.: Klimawandel und Trockengefährdung in der Landwirtschaft: Eine Analyse für die Steiermark, Wiss. Ber. 20-2008, Wegener Zentrum für Klima und Globalen Wandel, Graz, 2008. 
Kabas, T., Foelsche, U., and Kirchengast, G.: Seasonal and annual trends of temperature and precipitation within 1951/19712007 in south-eastern Styria, Austria, Meteorol. Z., under review, 2011.

Kirchengast, G., Kabas, T., Binder, S., Leuprecht, A., and Bichler, C.: Pionierexperiment WegenerNet Klimastationsnetz: Ein neuartiges Messnetz in der Region Feldbach (Steiermark/Österreich) zur Beobachtung von Wetter und Klima mit sehr hoher Auflösung, Wiss. Ber. 23-2008, Wegener Zentrum für Klima und Globalen Wandel, Graz, 2008.

Prettenthaler, F., Dalla-Via, A., Gobiet, A., Fank, J., Kurzmann, R., Oberauner, I., Töglhofer, C., Truhetz, H., and Zakarias, G.: Wasser und Wirtschaft im Klimawandel, in: Konkrete Ergebnisse am Beispiel der sensiblen Region Oststeiermark, edited by: Prettenthaler, F. and Dalla-Via, A., Vol. 1, Studien zum Klimawandel in Österreich, Verlag der Österreichischen Akademie der Wissenschaften, Wien, 2007.
Wulfmeyer, V., Behrendt, A., Bauer, H.-S., Kottmeier, C., Corsmeier, U., Blyth, A., Craig, G., Schumann, U., Hagen, M., Crewell, S., Girolamo, P. D., Flamant, C., Miller, M., Montani, A., Mobbs, S., Richard, E., Rotach, M. W., Arpagaus, M., Russchenberg, H., Schlüssel, P., König, M., Gärtner, V., Steinacker, R., Dorninger, M., Turner, D. D., Weckwerth, T., Hense, A., and Simmer, C.: The Convective and Orographically Induced Precipitation Study: A research and development project of the World Weather Research Program for improving quantitative precipitation forecasting in low-mountain regions, Bull. Am. Meteorol. Soc., 89, 1477-1486, doi:10.1175/2008BAMS2367.1, 2008. 